\title{
The distribution of drinking water-to-cattle ratios in the summer across four feedlots in the Texas High Plains
}

\author{
Raju Gautam ${ }^{1 *}$, Pablo J. Pinedo ${ }^{2}$, Sangshin Park ${ }^{1}$, Renata Ivanek ${ }^{1}$ \\ ${ }^{1}$ Department of Veterinary Integrative Biosciences, College of Veterinary Medicine and Biomedical Sciences, Texas A\&M Univer- \\ sity, College Station, USA; *Corresponding Author: rajugautam7@gmail.com, rgautam@cvm.tamu.edu \\ ${ }^{2}$ Texas A\&M AgriLife Research \& Extension Center, College of Veterinary Medicine and Biomedical Sciences, Texas A\&M Uni- \\ versity, Amarillo, USA
}

Received 16 April 2013; revised 17 May 2013; accepted 1 June 2013

Copyright (c) 2013 Raju Gautam et al. This is an open access article distributed under the Creative Commons Attribution License, which permits unrestricted use, distribution, and reproduction in any medium, provided the original work is properly cited.

\begin{abstract}
In this short communication, we report the findings of a cross-sectional pilot study of the amount of water available per head of cattle (water-to-cattle ratio) and the associated feedlot and environmental factors across 26 pens in four Texas feedlots. The water-to-cattle ratio varied greatly among pens within and between feedlots. Mixed-effect linear regression modeling with feedlot as a random effect indicated that water in troughs with a higher water-to-cattle ratio was generally warmer when compared with water in troughs with a lower water-to-cattle ratio. This may have implications in the transmission and persistence of pathogens in feedlot cattle, such as Shiga toxin-producing Escherichia coli and Salmonella, because warmer water has been reported to favor the growth of these pathogens. Therefore, future field studies in feedlot cattle are warranted to assess whether the water-to-cattle ratio affects the prevalence of these pathogens in the water itself or in feces shed by the animals.
\end{abstract}

Keywords: Water-Trough; Feedlot; Water-to-Cattle Ratio

\section{INTRODUCTION}

Drinking water is a critical component of everyday nutrition of feedlot cattle. Commercial feedlot operations manage drinking water in water troughs with an automatic refill system. The water refill system is designed to turn on and off automatically depending on the preset holding capacity of the water trough. Thus, water starts to flow into the trough when the water level goes below the preset holding capacity level, and the flow stops when the level is reached. Such a system for regulating the volume of water in the water trough minimizes water loss due to overflow, while ensuring the supply of an adequate amount of drinking water to the cattle at all times.

The daily water requirements of a feedlot cattle vary anywhere from 4 - 12 gallons per head of cattle depending on animal weight, diet, and ambient temperature [1]. Maintaining an adequate amount of clean drinking water for feedlot cattle is therefore essential to the welfare and productivity of animals. However, excess amounts of standing drinking water, particularly during warmer months, may also encourage pathogen growth (e.g., Shiga toxin-producing Escherichia coli (STEC)), increasing their concentration in water, and thereby facilitating the infection transmission among animals [2]. This undesirable effect is expected to be amplified in periods and regions characterized with warm weather because pathogen growth is strongly modulated by temperature [3, 4]. However, there is a lack of information about the water-to-cattle ratio and its variability in feedlot operations. Likewise, there is a knowledge gap in our understanding of how ambient temperature may affect the temperature of cattle drinking water in the feedlot. We report a crosssectional pilot study of 26 pens across four feedlots in the Texas Panhandle. The objectives of the study were: 1) to obtain information about variation in the ratio of the amount of drinking water over the number of cattle per pen under the existing feedlot operating conditions and 2) to determine the relationship between the ambient temperature and the drinking water temperature in feedlot pens. 


\section{MATERIALS AND METHODS}

We conducted a questionnaire-based survey of 13 feedlots in the Texas Panhandle to obtain preliminary information about the distribution of pen level waterto-cattle ratios and to elicit the feedlot's willingness to participate in the subsequent cross-sectional study. A total of 124 feedlot pens were covered during the survey. The feedlots were identified through one of the investigators' (PP) extension contacts. Of these 13 feedlots, 11 expressed their willingness to participate in the crosssectional study. Due to financial restrictions, only four of these feedlots were enrolled. The choice was based on the convenience related to the proximity among feedlots and the feedlot managers' cooperativeness, both of which were necessary to allow intensive sampling to be performed over two days, covering two feedlots per day. Six pens were selected for enrollment in three out of four enrolled feedlots, and eight pens were selected in the fourth feedlot. Purposive sampling was used in the selection of the feedlot pens, such that in a specific feedlot one-half of the enrolled pens constituted a higher number of animals per water trough and the other half consisted of a lower number of animals per water trough. This sampling strategy was implemented with the aim to capture the full extent of variation in the water-to-cattle ratios. A structured questionnaire was administered to the feedlot managers by personal interview to obtain information about the number of animals in the pen and the time in feeding. The number of water troughs in the pen, and whether the water troughs were exposed to the sun or managed under a shade were recorded by personal observations, while ambient and drinking water temperatures were measured using a graduated thermometer (Testo 110, maker: Testo). Measurement of the drinking water $\mathrm{pH}$ was made using a digital $\mathrm{pH}$ meter with temperature compensation (OYSTER-10, maker: Extech). Electrical conductivity of water was measured using portable probes (Digital Conductivity meter 09-327, maker: Fisher Scientific Traceable). The time of day the measurements of ambient and water temperatures were taken for a given pen was the same, but the time of day varied between pens. Information on water trough capacity was obtained by physical measurements of the length, width, and height of the water column in the water-trough using a measuring tape. To minimize measuring and recoding bias, all measurements were performed by one investigator (RG). Finally, water-to-cattle ratio was calculated by dividing the volume of water in the trough(s) with the number of cattle in the pen.

Summary statistics were calculated for all recorded variables. A statistical model was developed to assess the association of different pen-level factors (i.e., drinking water temperature, water $\mathrm{pH}$, water conductivity, length of time in feeding, and the water trough exposure to the sun) to the water-to-cattle ratio (the outcome variable). Screening of the individual variables for association with the outcome variable was performed by fitting a univariate regression model using a liberal cutoff $(\alpha=0.25)$ for the significance of association. In this analysis, the association between the outcome (water-to-cattle ratio) and the temperature of drinking water was assessed by using a variable that represented the difference between the ambient and water temperatures for a given pen (hereafter referred to as the "temperature difference") to account for the difference in measurement times during the day between pens. Variables that had a potential association with the outcome (i.e., a P-value < 0.25 ) based on the univariate analysis were considered in a multivariable mixed-effect linear regression model, which included the feedlot as the random effect to account for clustering of pens within feedlots. The final multivariable model was selected using a forward selection procedure based on the Akaike's information criterion (AIC) of all nested models and the significance of the variables in the model was determined at $\alpha=0.05$. Model assumptions for normality and equal variance were assessed by generating normal probability and residual plots using the model residuals.

Statistical analysis was also conducted to assess the potential relationship between the temperature of the drinking water (the dependent variable) and ambient temperature of the pen (the explanatory variable). The relationship was assessed based on the graphical plotting of all data points and a linear regression model developed for the subset of data on water troughs (from 20 pens) that were exposed to the sun. All statistical analyses were performed in R 2.13.1 version (R Development Core Team, 2011) of the software package for statistical computing.

\section{RESULTS AND DISCUSSIONS}

The overall distribution of the water-to-cattle ratio in the 13 surveyed feedlots is shown in Figure 1(a). The median water-to-cattle ratio was 0.25 gallons/head with a median absolute deviation (MAD) of 0.11 . While the middle $50 \%$ of the water-to-cattle ratios were in a relatively narrow range between 0.2 and 0.34 gallons/head, the bottom and particularly the top quartiles indicated considerable variation (Figure 1(a)). Figure 1(b) illustrates the distribution and variation in the water-to-cattle ratios for each of the four feedlots enrolled in the cross-sectional study. For these four feedlots, the median water-to-cattle ratio was 0.30 gallons/head with MAD of 0.24 . The purposive selection of pens with lower and higher values of water-to-cattle ratio captured the tails of the distribution of water-to-cattle ratios with an over 


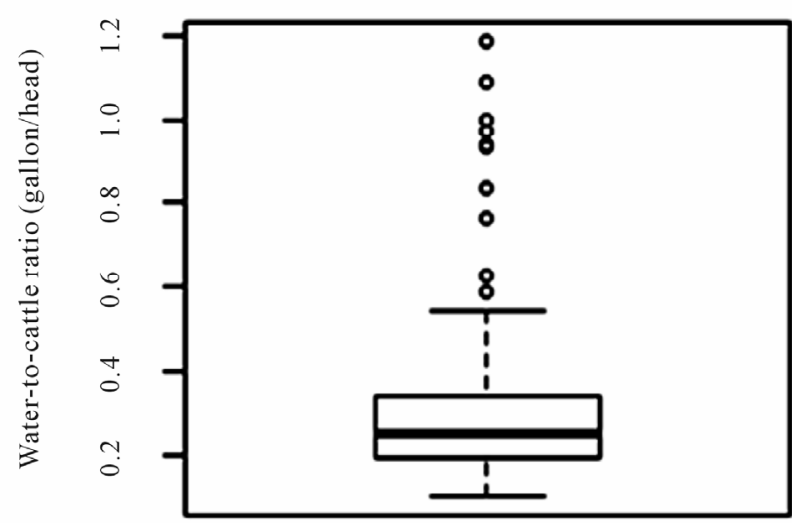

(a)

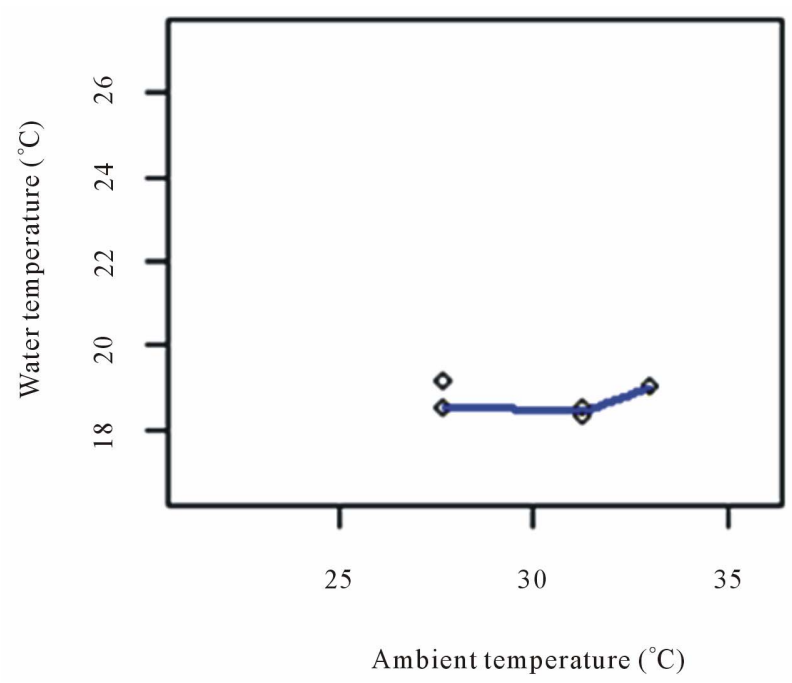

(c)

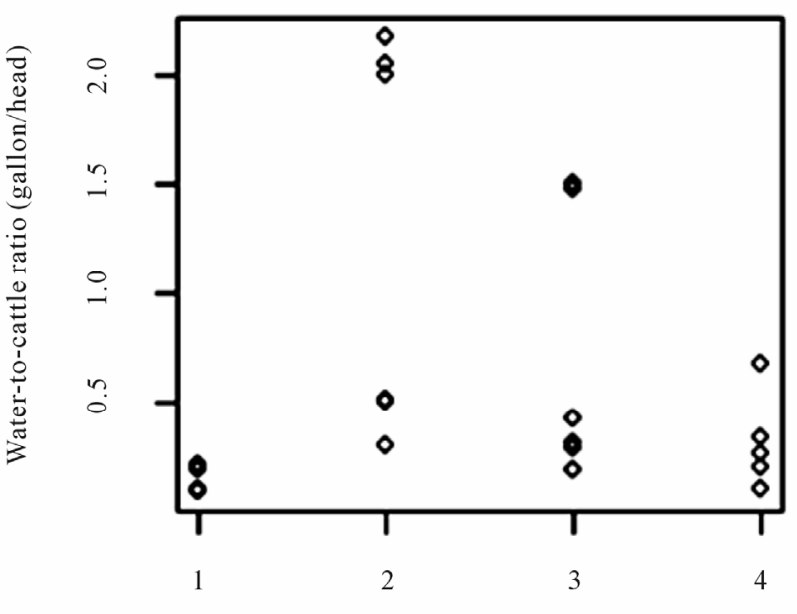

Feedlot ID

(b)

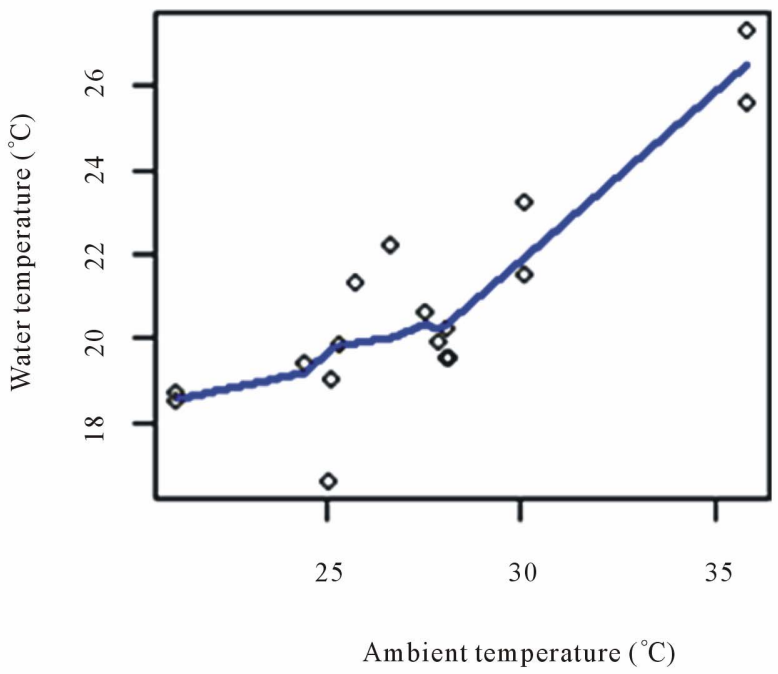

(d)

Figure 1. (a) A box plot of the distribution of the overall water-to-cattle ratio in 13 surveyed feedlots; (b) The pen-specific water-tocattle ratios for each of the four feedlots enrolled in the cross-sectional study. In the lower panel, the relationship between the ambient temperature and drinking water temperature managed (c) under the shade and (d) exposed to the sun.

representation of the higher values (Figure 1(b)). However, notably, some pens had the water-to-cattle ratio of 1.5 gallon/head or above while the highest ratios reported in the survey were at around 1.2 gallons/head suggesting that the survey-based water-to-cattle ratios were underestimated due to the recall bias. Alternatively, the difference may be reflective of the dynamic nature of the water-to-cattle ratio, which may have changed if the number of animals moving in and out of the pens changed between the two time points of the study. Figures 1(c) and (d) show the relationships between the temperature of drinking water and the ambient temperature of the pen for drinking water managed under shade and exposed directly to the sun, respectively. Based on the visual in- spection of the plots, there was no apparent increase in the drinking water temperature with an increase in the ambient temperature of the pen for water maintained under the shaded area. However, when water was directly exposed to the sun, the water temperature increased linearly with the increase in the ambient temperature of the pen. For every $1^{\circ} \mathrm{C}$ increase in the ambient temperature, the temperature of drinking water directly exposed to the sun increased on an average by $0.53^{\circ} \mathrm{C}, \mathrm{SE}=0.08\left(\mathrm{P}\right.$-value $<0.0001$, adjusted $\mathrm{R}^{2}=$ 0.71 ).

For the model exploring the relationship between the pen-level factors and water-to-cattle ratio, univariate analysis indicated two fixed effects (the "temperature 
difference" and water conductivity) to be linearly related with the water-to-cattle ratio. The variance component of the random effect was 0.18 , which constituted approximately $50 \%$ of the total variation and the remainder $(0.2)$ was attributed to the residual error. The large amount of variation attributed to the random component suggests that there is a wide variation in the water-to-cattle ratio from one feedlot to another. For every $1^{\circ} \mathrm{C}$ increase in the "temperature difference" between the ambient and water temperatures there was a corresponding decrease of $0.085(\mathrm{SE}=0.044)$ gallons $(300 \mathrm{ml}) /$ cattle in the water-to-cattle ratio $(\mathrm{P}$-value $=0.03$ ) when controlling for water conductivity and the feedlot. This means that pens with a lower water-to-cattle ratio tend to have cooler drinking water. This can be explained by a faster refilling of the water troughs with fresh water, which implies that the standing drinking water in the troughs is exposed to high ambient temperature for a shorter period of time. On the contrary, a high water-to-cattle ratio is related to a slower rate of trough refilling and consequently the water is exposed to high ambient temperature for a longer period of time. In other words, water in troughs with high water-to-cattle ratio is generally warmer. Because warmer water may promote faster growth of bacteria important to food safety $[3,4]$, it would appear that having a lower water-to-cattle ratio, which does not adversely affect the adequate supply of drinking water, may actually be a tool to control transmission of the infections mediated through contaminated water. Alternatively, a system to allow continuous flow of water in the water trough may be used to prevent steep rise of drinking water temperature with the increase in ambient temperature during a summer day. However, lowering the water-to-cattle ratio is likely to be a more attractive choice to the feedlot owners because it would benefit the beef industry through a better use of an already limited water resource in feedlot operations in the Texas High Plains. One of the important factors that could affect the refill rate of water in the pen is the age of animals because heavier (adult) cattle in the feedlot are expected to be drinking more water and thus increase the rate of refill even if the water-to-cattle ratio is the same. While we did not have information on age, we used animal time in feeding as a proxy to assess if it significantly affected the water-to-cattle ratio. The univariate analysis did not suggest that time in feeding significantly affected the observed water-to-cattle ratio in this study and therefore, we believe that the age effect could be ignored.

Previously, it had been reported that the prevalence of E. coli $\mathrm{O} 157: \mathrm{H7}$ in weaned calves could be reduced by replacing large-volume water tanks with small volume water troughs that facilitated high turnover rate of drinking water [5]. Several other studies tried to relate contamination of drinking water with shedding prevalence of E. coli $\mathrm{O} 157: \mathrm{H} 7$ and the findings were inconclusive [6-8]. However, these studies did not consider the potential effect of increased water temperature on pathogen replication and the consequence of higher bacterial concentrations on $E$. coli $\mathrm{O} 157: \mathrm{H} 7$ shedding prevalence in cattle. While the variation in the water-to-cattle ratio observed in this study, between 0.2 and 1.2 gallons/head, may not at the first glance appear meaningfully wide, the variation is however, sufficient to allow for a significantly increased temperature of drinking water for higher values of the water-to-cattle ratios. Thus, the results of this study suggest that the assessment of the relationship between water-to-cattle ratio and prevalence of pathogens in feedlots, such as E. coli O157:H7, is worth pursuing further. Similarly, the information on replication of $E$. coli $\mathrm{O} 157: \mathrm{H7}$ in drinking water in feedlots is lacking and whether the replication reported by Vital et al. [3] in distilled water applies to the drinking water in feedlots needs to be verified under experimental conditions.

The association between the water-to-cattle ratio and water conductivity was marginally significant $(\mathrm{P}$-value $=$ 0.07). For every one unit increase in water conductivity, there was an associated decrease in water-to-cattle ratio of 0.15 gallons $(0.568 \mathrm{ml}) /$ head of cattle $(\mathrm{SE}=0.1)$ after controlling for the temperature difference and the feedlot. In other words, water that refills faster has higher conductivity. The validity of and the mechanism behind this association is unclear. Generally, conductivity of water is influenced by the concentration of inorganic dissolved solids such as chloride, nitrate, sulphate, sodium, and magnesium, as well as water temperature [9].

The pilot study described here has important limitations due to the small number of enrolled feedlot operations, the narrow geographic study area covered, and the observational study design used. However, the findings may be of importance to the beef industry and food safety. Moreover, while no prior information was available to allow estimation of sample size in the current study, this report could support sample size estimation in the future.

\section{CONCLUSION}

There is a wide variation in the water-to-cattle ratio among feedlots in the Texas Panhandle. The water-tocattle ratio was associated with temperature, which was an important factor that affected pathogen (e.g., STEC and Salmonella) growth in drinking water for animals. Therefore, future field studies should be conducted to assess the association between the water-to-cattle ratio and the prevalence of the corresponding infections in feedlots.

\section{ACKNOWLEDGEMENTS}

This work was supported by the Texas A\&M University's College of Veterinary Medicine Graduate Student Research Proposal Award to RG and the National Science Foundation grant NSF-EF-0913367 to RI 
funded under the American Recovery and Reinvestment Act of 2009. Any opinions, findings, and conclusions or recommendations expressed in this material are those of the authors. The authors gratefully acknowledge the assistance of the Texas Cattle Feeders Association in contacting the participating feedlots.

\section{REFERENCES}

[1] Boyles, S., Loerch, S., Fluharty, F., Shulaw, W. and Stanfield, H. Feedlot management primer. In: Beef Information, Ohio State University Extension. http://beef.osu.edu/library/feedlot/feedlot.pdf

[2] Gautam, R., Bani-Yaghoub, M., Neill, W.H., Döpfer, D., Kaspar, C. and Ivanek, R. (2011) Modeling the effect of seasonal variation in ambient temperature on the transmission dynamics of a pathogen with a free-living stage: Example of Escherichia coli O157:H7 in a dairy herd. Preventive Veterinary Medicine, 102, 10-21. doi:10.1016/j.prevetmed.2011.06.008

[3] Vital, M., Hammes, F. and Egli, T. (2008) Escherichia coli $\mathrm{O} 157$ can grow in natural freshwater at low carbon concentrations. Environmental Microbiology, 10, 23872396. doi:10.1111/j.1462-2920.2008.01664.x

[4] Wang, G., Zhao, T. and Doyle, M.P. (1996) Fate of enterohemorrhagic Escherichia coli O157:H7 in bovine fe- ces. Applied Environmental Microbiology, 62, 2567-2570.

[5] Kaspar, C.W. (2009) Waterborne dissemination of Escherichia coli O157:H7. Unite States Food and Drug Administration. http://www.fda.gov/AnimalVeterinary/NewsEvents/CVM Updates/ucm138286.htm

[6] LeJeune, J.T., Besser, T.E., Merrill, N.L., Rice, D.H. and Hancock, D.D. (2001) Livestock drinking water microbiology and the factors influencing the quality of drinking water offered to cattle. Journal of Dairy Science, 84, 1856-1862. doi:10.3168/jds.S0022-0302(01)74626-7

[7] LeJeune, J.T., Besser, T.E., Rice, D.H., Berg, J.L., Stilborn, R.P. and Hancock, D.D. (2004) Longitudinal study of fecal shedding of Escherichia coli O157:H7 in feedlot cattle: Predominance and persistence of specific clonal types despite massive cattle population turnover. Applied Environmental Microbiology, 70, 377-384. doi:10.1128/AEM.70.1.377-384.2004

[8] LeJeune, J.T., Besser, T.E. and Hancock, D.D. (2001) Cattle water troughs as reservoirs of Escherichia coli O157. Applied Environmental Microbiology, 67, 30533057. doi:10.1128/AEM.67.7.3053-3057.2001

[9] Environmental Protection Agency (2012) Conductivity. In: Water: Monitoring and Assessment, Washington DC. http://water.epa.gov/type/rsl/monitoring/vms59.cfm 